OPEN ACCESS

Edited by:

Yuan-Pang Wang,

University of São Paulo, Brazil

Reviewed by: Jose Antonio López-Pina University of Murcia, Spain

S. M. Yasir Arafat,

Enam Medical College, Bangladesh

*Correspondence: Francisco Alcantud-Marín francisco.alcantud@uv.es

Specialty section

This article was submitted to Mood and Anxiety Disorders,

a section of the journal

Frontiers in Psychiatry

Received: 30 July 2020 Accepted: 19 January 2021 Published: 11 February 2021

Citation:

Sánchez-Cueva S, Alonso-Esteban Y, Sánchez-Cueva P, Birmaher B and Alcantud-Marín F (2021)

Psychometrics of the Spanish Version of the Screen for Adult Anxiety Related

Disorders (SCAARED).

Front. Psychiatry 12:589422.

doi: 10.3389/fpsyt.2021.589422

\section{Psychometrics of the Spanish Version of the Screen for Adult Anxiety Related Disorders (SCAARED)}

\author{
Sarah Sánchez-Cueva ${ }^{1}$, Yurena Alonso-Esteban ${ }^{1}$, Patricio Sánchez-Cueva ${ }^{2}$, \\ Boris Birmaher ${ }^{3}$ and Francisco Alcantud-Marín ${ }^{1 *}$
}

${ }^{1}$ Department of Developmental and Educational Psychology, University of Valencia, Valencia, Spain, ${ }^{2}$ College of Medicine, Pennsylvania State University, Hershey, PA, United States, ${ }^{3}$ Department of Psychiatry, University of Pittsburgh Medical Center, Pittsburgh, PA, United States

Objectives: To translate and validate the Screen for Adult Anxiety Related Disorders (SCAARED) questionnaire into Spanish.

Method: The original SCAARED was translated into Spanish and administered to a non-clinical sample of 131 university students (92.4\% women, mean age 22 years) in Valencia, Spain. To assess the concurrent validity of the SCAARED, the Depression, Anxiety and Stress Scale-21(DASS) and the Beck's Anxiety Inventory (BAl) were also administered. Test-retest reliability was evaluated 2 weeks after the first administration.

Results: The internal consistency of SCAARED was high $(\alpha=0.91)$ and the stability of the measurement was also high (test-retest 0.81). The results of the Exploratory Factor Analysis showed four factors comparable to the original SCAARED (generalized anxiety disorder, social phobia disorder, panic disorder, and separation anxiety disorder). The Area Under the Curve was excellent (0.88).

Conclusions: The Spanish version of the SCAARED showed good psychometric properties comparable to the original SCAARED suggesting that it may be a useful instrument to screen for anxiety disorders in Spanish-speaking adult populations. Future studies are needed to replicate these findings in larger community and clinical samples.

Keywords: anxiety disorders, anxiety measures, rating scales, tools translation, measure of anxiety in adults

\section{INTRODUCTION}

Anxiety disorders including generalized anxiety disorder, social anxiety disorder, panic disorder, agoraphobia and specific phobia, are among the most common psychiatric disorders in youths and adults with $4-25 \%$ of people suffering from one or more anxiety disorders in their lives $(1,2)$.

There has been a growing interest in research on anxiety disorders in the last decade, partly due to greater recognition of their burden and the impact of untreated illnesses (3). Results from a recent review and meta-analysis indicate that the majority of anxiety disorders tend to have an early onset, generally in childhood or early adolescence $(4,5)$, and endure over time if not properly treated. Anxiety disorders experienced before or during early adulthood have been associated with poor psychosocial functioning (e.g., work), poor health, low life satisfaction, and less social relationships during adulthood $(6,7)$. In addition, there is substantial evidence to suggest that individuals with anxiety disorders are at risk to develop substance abuse $(5,8)$; chronical medical illness (8); depressive disorders $(9,10)$; suicide-related behaviors or other risky behaviors (11). 
Unfortunately, anxiety disorders may be unrecognized, particularly when is comorbid with other disorders such major depression, making treatment ineffective. The high prevalence of anxiety disorders among youth and adults and the resulting consequences recommend early detection to identify anxiety symptoms in these age groups. One of the factors that influence the under recognition of anxiety disorders is the limitations of current screening instruments $(12,13)$ in typically developing adult's populations (14) and among people with neurodevelopmental disorders (15). The use of structured (or semi-structured) interviews to evaluate anxiety disorders is the procedure of choice for establishing the diagnosis of an anxiety disorder (16), but is time-consuming and requires extensive training from either Primary Health Care professionals, clinical psychologists, and researchers. Consequently, self-report measures are the most common method of anxiety assessment $(12,17)$. Still, access to good screening instruments (with good levels of reliability, validity, and diagnostic discrimination), including formats for various informants (e.g., parents, teachers, self-reporters) and are affordable and adapted to Spanishspeaking populations, is often limited.

Currently, the most popular instruments for assessing anxiety in adults, include the State-Trait Anxiety Inventory (STAI) (18) and the Beck Anxiety Inventory (BAI) (19), two empirically and widely validated instruments used in psychological research and clinical practice in Spain $(20,21)$. Also, the Depression, Anxiety, and Stress Scale (DASS-21) (22), has shown promise in the screening for anxiety symptoms. Several other validated and reliable anxiety measures for specific anxiety disorders exist including, among others, the Generalized Anxiety Disorder Questionnaire and Generalized Anxiety Disorder-7 Scale (GADQ-IV \& GAD-7) (23); the Social Phobia Inventory (SPIN) (24), the Liebowitz Social Anxiety Scale (LSAS) (25); and the Panic Disorder Severity Scale (PDSS) (26).

One of the limitations of the above scales is that they mainly assess one or two specific anxiety disorders. Although informative, this may be problematic because anxiety disorders usually are comorbid within themselves (27). Recently, a screen for all DSM-5 (28) was developed, the Screen for Adult Anxiety Related Emotional Disorders (SCAARED) (29). The SCAARED is a 44-item self-report instrument that was adapted from the youth instrument, the Screen for Children Anxiety Related Emotional Disorders (SCARED) $(30,31)$, a rating scale developed to screen for DSM anxiety disorders in youth (32). Numerous studies and meta-analysis have examined the psychometric properties of the SCARED, indicating good psychometric properties for children and adolescents from various countries and on different language adaptations (32-34). The factorial structure of SCAARED shows a correspondence with the SCARED including four factors that correspond to the respective diagnostic categories of DSM-5, including agoraphobia, panic disorder, generalized anxiety, social anxiety, and separation anxiety disorder (29). The SCAARED has excellent internal consistency ( $\alpha$ by Cronbach $=0.97$ ).

In addition to its good psychometric properties, as eluded before, in contrast to the other available rating scales for anxiety disorders in adults which usually only include one anxiety disorder, the SCAARED includes all DSM-5 anxiety disorders. Moreover, the fact that the SCAARED was derived from the SCARED and share similar factors, allows to compare the scores of the two instruments between adults and youth and follow up studies from childhood into adulthood.

Many of the adult anxiety questionnaires noted above have been translated to Spanish [e.g.,: DASS-21 (35) STAI (36)], but not the SCAARED. Thus, the goals for this study were to: (1) To translate the (SCAARED) into Spanish and validate it in a non-clinical sample to verify its factor structure and its reliability (internal consistency and stability of the measurement); (2) To examine the concurrent validity of the Spanish translation of the SCAARED with the Depression, Anxiety and Stress Scale (DASS21) (37) and the Beck Anxiety Inventory (BAI) (19) and (3) To analyze the construct validity by means of a factorial analysis to check the stability of the original model.

\section{METHOD}

\section{Procedure and Participants}

The sample comprised 131 college students ( $92.4 \%$ female, mean age 22 years old, all Caucasian), recruited from the University of Valencia, Spain, using non-probability and convenience sampling. Participants were informed about the PICCA project [Programa de Intervención Cognitivo-Conductual en Ansiedad (Cognitive Behavioral Intervention Program for Anxiety)], requesting their collaboration on a voluntary basis. Prior to data collection, the purpose, procedures, and expectations of the study were described to all participants All third-year students of the Faculty of Education (specialty of Therapeutic Pedagogy and Hearing and Language) and of the Faculty of Psychology and Speech Therapy (specialty of speech therapy), completed the Spanish version of the SCAARED at the same time they completed the BAI and the DASS-21. The administration of the battery was carried out during the rest time between two classes at the beginning of the second term of the 2019-20 academic year (first week of February). Participants completed the questionnaires independently, although in a collective/group session carried out in the presence of one of the investigators.

Following the completion of the questionnaires, we contacted the students who showed significant anxiety symptoms and agreed to be re-contacted by e-mail to participate in the clinical interview for confirmation of the diagnosis and, if appropriate, participate in PICCA. Participants who agreed returned for assessments at time 2 (15 days later) for administration retest reliability and diagnostic interview. The clinical interview was performed by a specialized psychologist (co-author of the study), administered a subset of relevant International Neuropsychiatric Interview chapters (38). This study was approved by the University of Valencia's Human Research Ethics Committee (H1549280336722). Consent was obtained from participants in accordance with the University of Valencia's Human Research Ethics Committee.

\section{Measures}

The SCAARED (29) was translated, following the guidelines for translation and adaptation of Psychological Assessment 
instruments (39). After consulting the author and obtaining his consent, the English version of the questionnaire was initially translated by a bilingual psychologist, who proposed a first translation of the items into Spanish. In some cases, small adaptations were made since the literal translation could be misleading. A second translator performed the same task, to

TABLE 1 | Descriptive statistics of the 44 items of SCAARED.

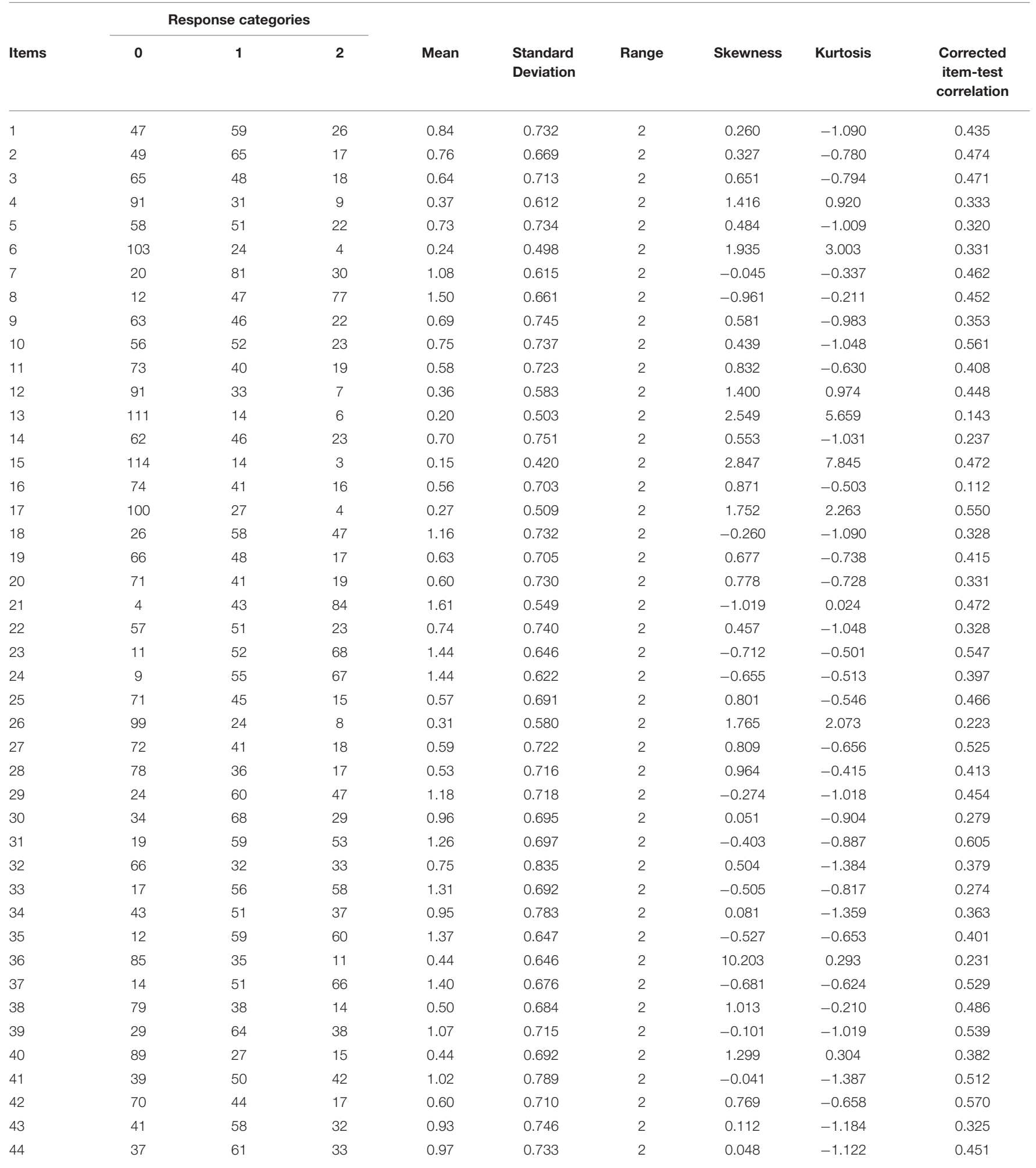


later reach a consensus on the modifications, and thus be able to propose a single translation. Finally, a back-translation into English was made, which was evaluated by the author of the scale to judge the adjustment of the terms used. The final version of the SCAARED in Spanish is the object of this study (see Supplementary Material 1).

To evaluate the validity (criteria, content, construct) of the SCAARED in Spanish, two existing anxiety self-reports were also administered. The DASS-21 is a short version derived from the full 42-item self-report scale DASS (37), which measures negative emotional states (Anxiety, Stress and Depression) with a selection of 7 elements from each construct. The DASS-21 has validated versions in Spanish, reporting adequate psychometric properties in the general adult population (40), in university students $(22,41)$, and in the clinical population (35). The Spanish version of the DASS-21 self-report instrument was used for this study (22).

The BAI (19) is a 21-item self-report instrument that is used for measuring the typical symptoms of anxiety disorders. It is designed to assess the severity of anxiety symptoms and is widely used in both clinical and research settings. Each item refers to symptoms experienced in the last week and is answered with a 4 -point severity scale. The total score on the scale ranges from 0 to 63 points. There is a Spanish version (19) with excellent psychometric performance both in university students (42), in the general population general (43), and especially in the clinical population $(44,45)$.

\section{Data Analysis}

The descriptive statistical analyses were performed with the SPSS (V26) licensed by the University of Valencia (Spain), the dimensionality analysis will be carried out with the software Mplus 8.3 (46). First, the descriptive statistical and the psychometric analysis of the SCAARED items was performed by calculating of mean, standard deviation, range, kurtosis, asymmetry, and corrected item-test correlation of all items on the scale and the internal consistency indicators (Cronbach's Alpha) and correlations with the other measures. The stability of the measurement (test-retest validity) was calculated with in a subsample of participants $(n=19) 15$ days later. Receiver Operating Characteristic (ROC curve analysis) were used to determine SCAARED relative diagnostic accuracy. To analyze the structure of SCAARED a Confirmatory Factor Analysis (CFA) was developed on the original model (29). Additionally, we propose to perform an Exploratory Factorial Analysis (EFA) on the same data in order to venture a possible dimensionality different from the proposal in SCAARED original model.

\section{RESULTS}

The descriptive results of the 44 items of the SCAARED are shown in Table 1 in the Supplementary Material of this article (see Supplement S1). The value of the correlation between each item and the test shows low to medium values $(0.11-0.60)$ and the indices of asymmetry and kurtosis that the distribution of response frequencies in the three item alternatives (Likert Type) show non-normal behavior. For the present validation study of the SCAARED in Spanish, we will consider the values of the original scale (29).

The Cronbach's alpha for the total SCAARED scale was adequate $(\alpha=0.91)$, and very acceptable internal consistency for the items in each of the four dimensions of the scale (PA/SO $\alpha=0.84$; GA $\alpha=0.85$; SEP $\alpha=0.62$; SOC $\alpha=0.91$ ). As shown in Table 2, the test-retest correlations are high $(<0.81)$ in all dimensions and in the total of the test. The $t$-tests for related samples show that the scores are stable 15 days after the first application.

TABLE 2 | Means, standard deviations, Pearson's $r_{x y}$ and t-student comparing test and re-test results for each of the SCAARED dimensions.

\begin{tabular}{|c|c|c|c|c|c|c|c|}
\hline \multirow[t]{2}{*}{ SCAARED } & \multicolumn{2}{|c|}{ First time } & \multicolumn{2}{|c|}{ Second time } & \multirow[b]{2}{*}{$\mathbf{r}_{\mathrm{xy}}$} & \multirow[b]{2}{*}{$t$} & \multirow[b]{2}{*}{$p$} \\
\hline & Mean & STD & Mean & STD & & & \\
\hline Total & 54.21 & 10.79 & 53.21 & 12.28 & 0.92 & 0.78 & 0.45 \\
\hline Panic disorder & 16.28 & 7.31 & 16.21 & 6.50 & 0.95 & 0.11 & 0.91 \\
\hline Generalized anxiety disorder & 22.36 & 2.95 & 21.50 & 3.82 & 0.87 & 1.71 & 0.11 \\
\hline Separation anxiety disorder & 5.29 & 2.64 & 5.36 & 2.13 & 0.81 & -0.17 & 0.86 \\
\hline Social anxiety disorder & 10.29 & 3.29 & 10.00 & 3.39 & 0.86 & 0.34 & 0.74 \\
\hline
\end{tabular}

TABLE 3 | Correlations between DASS-21 and BAI tests and SCAARED dimensions $(N=131)$.

\begin{tabular}{|c|c|c|c|c|}
\hline SCAARED & DASS-21 stress & DASS-21 anxiety & DASS-21 depression & BAl \\
\hline TOTAL & 0.67 & 0.73 & 0.60 & 0.73 \\
\hline Panic disorder & 0.58 & 0.71 & 0.50 & 0.68 \\
\hline Generalized anxiety disorder & 0.66 & 0.57 & 0.53 & 0.60 \\
\hline Separation anxiety disorder & 0.26 & 0.34 & 0.19 & 0.42 \\
\hline Social anxiety disorder & 0.30 & 0.36 & 0.39 & 0.36 \\
\hline
\end{tabular}

$p$-values $\leq 0.05$. 
TABLE 4 | The Area Under the Curve (AUC) of the Receiver Operating Characteristic (ROC) curve and total fitting rates of the predictive model.

\begin{tabular}{|c|c|c|c|c|c|c|c|c|c|c|c|}
\hline SCAARED & AUC, 0.0 , & 0.10 & 0.20 & 0.30 & 0.40 & b.50, & 0.60 & 0.70 & 0.80 & 0.90 & 1.0 \\
\hline Panic disorder & 0.85 & & & & & & & & 0.75 & & \\
\hline Generalized anxiety disorder & 0.83 & & & & & & & & 0.73 & & \\
\hline Separation anxiety disorder & 0.62 & & & & & 0.48 & & & & & \\
\hline
\end{tabular}

Regarding concurrent validity, the DASS-21 and BAI tests were applied simultaneously to the SCAARED. Table 3 shows the correlation indices between the scores of the SCAARED dimensions and each of the tests used as criteria. Note that all correlations were significant ( $p$-values $\leq 0.05)$ with the lowest being for Separation Anxiety.

The diagnostic value was assessed by taking as a criterion having reached the cut-off point in the DASS-21 and in the BAI tests. The ROC curve was examined for each of the SCAARED subscales and for the total score. As shown in Table 4, the values of the area under the curve and the fitting model. The AUC Index value of the 0.88 total test can be considered very adequate. This is the same as the predicted values of AG (0.83) and TP/S (0.85). However, TAS (0.62) and AS (0.72) constructs are not properly adjusted. When analyzing the ROC curve data, the diagnostic contrast criteria used must be taken into account.

A confirmatory factorial analysis with Mplus version 8.3 (46) was conducted on the original model of SCAARED (29). The values of RMSEA (0.085), the Tucker Lewis Index (TLI =0.621) and the comparative fit index $(\mathrm{CFI}=0.641)$ are close to the critical values in each case, the SRMR (0.112) although the $\chi^{2}$ value is significant the final fit to the model $\left(\chi^{2}=3,545.71 ; p=\right.$ 0.00 ), point to an inadequate fit of the data to the original model.

Because the original structure was not confirmed, we carried out an EFA on the same sample to venture a possible dimensionality different from the proposal in the CFA. An EFA was performed on the 44 items and same sample. The KaiseMeyer-Olkin index of sampling adequacy is 0.76 and Bartlett's sphericity test is significant $\left(\chi^{2}=1,464.1 ; \mathrm{df}=861 ; p=0.0\right)$, indicating that although the sample is small, we can proceed with the analysis (47).

The EFA was conducted to verify the four factor structure with Mplus. The values RMSEA (0.046), the TLI (0.92), CFI (0.93), $\operatorname{SRMR}(0.0866)$ and $\chi 2$ value $(4,529.38 ; p=0.00)$ indicate a good fit in the four-factor solution found and shown in Table 5. The first factor replicates the construct of Generalized Anxiety; the second factor rebuilds the construct of Panic Disorder. The third factor is defined by the items related to Social Anxiety and the fourth factor is defined by the items of Separation Anxiety.

\section{DISCUSSION}

The aims of this study were to translate the SCAARED questionnaire (29) into Spanish and evaluate its psychometric properties in a sample of 131 college students. Overall, the results from the Spanish version of the SCAARED indicated good internal consistency (Cronbach $\alpha>0.90$ ), 2-week testretest reliability $(>0.86 ; p=0.001)$, and adequate convergent validity with the DASS-21 and BAI. The results of the ROC analysis (AUC 0.88) inform us of excellent predictive value. The lowest correlation between the SCAARED and these instruments was with Separation Anxiety Disorder dimension because this disorder was only recently included in the DSM-5 as an adult anxiety disorder and as expected, except for the SCAARED, other anxiety self-reports do not include symptoms for this disorder.

The results of the Exploratory Factor Analysis showed four-factor structure (Generalized Anxiety, Social Anxiety, Panic Disorder/Significant Somatic Symptoms, and Separation Anxiety), which are consistent with the original SCAARED and correspond to the four factors reported for the instrument to screen for anxiety disorders in youth, the SCAARED (29). Moreover, the results of diagnostic validity, evaluated by means of the AUC indicators of the ROC curve were satisfactory. The above noted findings indicate that the Spanish version of the SCAARED behaves similarly to the English version and therefore appears to be an appropriate instrument for screening anxiety disorders in Spanish speaking adult populations. The fact that there are also Spanish versions of SCARED to screen youth for anxiety disorders $(33,34)$ with similar factorial structures, allows to use them as tools for evaluation of anxiety symptomatology in parents and their children and longitudinal studies of anxiety symptoms from childhood into adulthood.

Other adult anxiety measures available in Spanish are either dimensional (DASS-21; BAI; STAI, etc.) or specific to only one disorder (GAD-Q-IV, SPIN, LSAS, PDSS, etc.). In contrast, the SCAARED provides information on four types of anxiety disorders described in the DSM-5 and has excellent psychometric properties. In addition, it can be easily administered, is freely accessible, and time-effective (5-10 min). Finally, as noted above, the SCAARED can be crucial in obtaining and contrasting information from the patient/participant throughout life, since it bears similarities with the SCARED scale of which a Spanish version is already available (34).

Several limitations of our study are worth mention including a relatively small sample size, most of which were females and being a non-clinical sample which has impeded the calculation of some psychometric properties, such as inter-rater reliability and discriminatory validity. Consequently, further studies including larger samples and in clinical populations are needed. The present study consisted of the translation and adaptation of the scale and consequently, no qualitative 
TABLE 5 | Factor Analysis for the four-factor solution (Saturations below 0.30 have been excluded).

\begin{tabular}{|c|c|c|c|c|}
\hline $\boldsymbol{N}$ Item & $\begin{array}{c}\text { Factor I } \\
\text { Generalized } \\
\text { anxiety disorder }\end{array}$ & $\begin{array}{l}\text { Factor II } \\
\text { Social phobia } \\
\text { disorder }\end{array}$ & $\begin{array}{c}\text { Factor III } \\
\text { Panic } \\
\text { disorder/significant } \\
\text { somatic } \\
\text { symptoms }\end{array}$ & $\begin{array}{c}\text { Factor IV } \\
\text { Separation } \\
\text { anxiety disorder }\end{array}$ \\
\hline
\end{tabular}

21 I worry about things working out for me, [Le preocupa cómo le van a

22 When I get anxious, I sweat a lot, [Cuando me siento ansioso(a), sudo mucho]

34 I feel shy with people I don't know well, [Me siento tímido(a) con gente que no conozco bien]

27 It is hard for me to talk with people I don't know well, [Es difícil para mí hablar con gente que no conozco bien]

03 I don't like to be with people I don't know well, [No me gusta estar con personas que no conozco bien]

43 I am shy, [Soy tímido(a)]

10 I feel nervous with people I don't know well, [Me siento nervioso(a) con personas que no conozco bien]

42 I feel nervous when I go to parties, dances, or any place where there will 
TABLE 5 | Continued

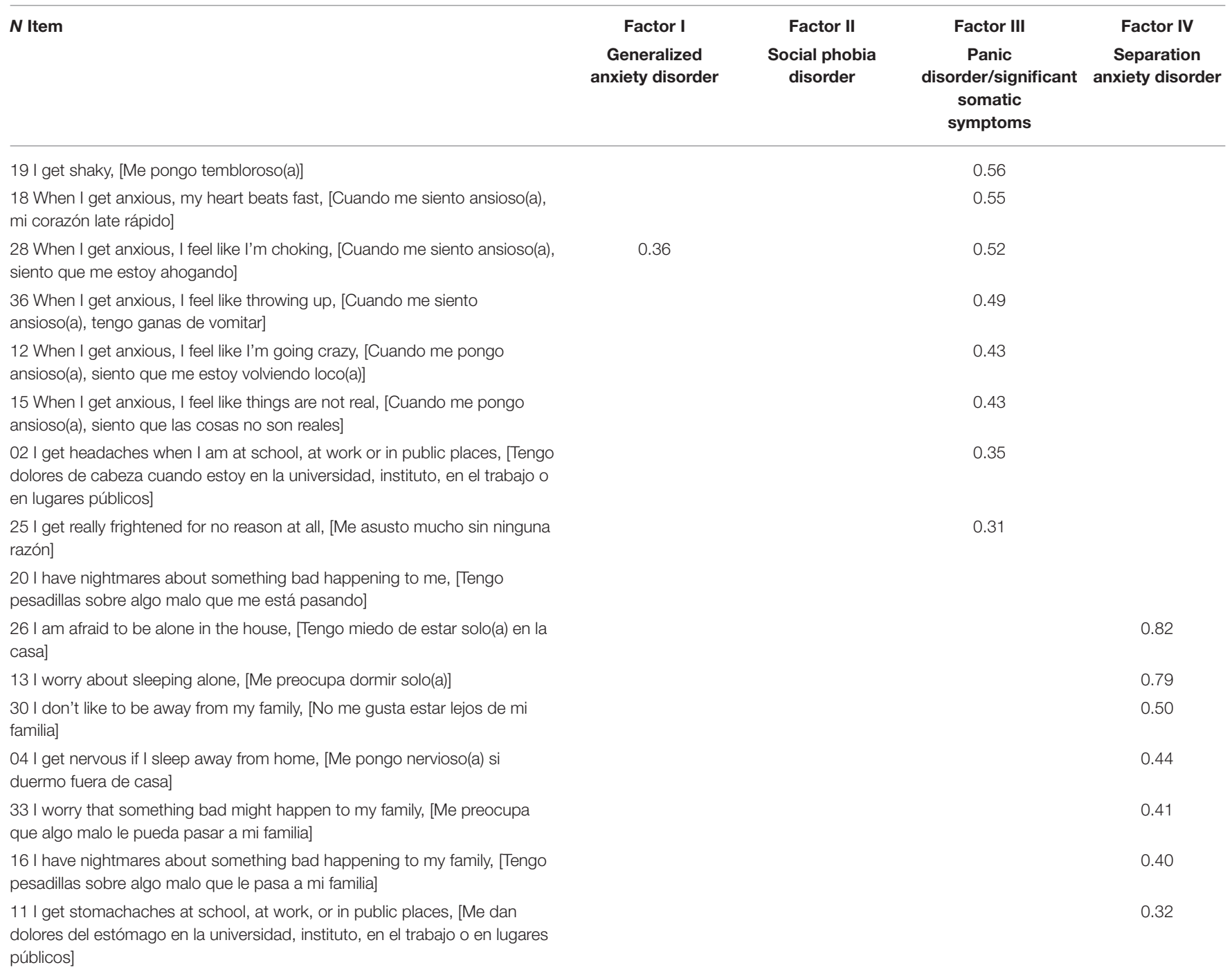

Factor I: Items 5, 7, 8, 9, 14, 21, 23, 28, 29, 31, 35, 37, 39, 44.

Factor II: Items 3, 5, 10, 14, 17, 27, 34, 37, 38, 41, 42.

Factor III: Items 1, 2, 6, 12, 15, 18, 19, 25, 28, 32, 36, 40.

Factor IV: Items 4,11, 13,16, 26, 30, 33.

studies (e.g., discussion groups) have been conducted on the comprehensibility of items in the Spanish. Nevertheless, the authors carefully reread the items in both languages to assess comprehensibility and changes were incorporated when consensus indicated that a change improved the translation. Likewise, during the administration of the questionnaire, special attention was paid to the evaluation of the meaning of each element, without giving rise to significant questions or observations on the part of the people participating in the study.

In summary, similar to the English version of the SCAARED, the Spanish version showed good psychometric properties suggesting that it is a potential tool to screen for DSM-5 anxiety disorders in non-clinical adult populations. Further studies in large samples of clinical populations are necessary to evaluate its sensitivity and specificity as well as cut-off points to screen for anxiety disorders.

\section{DATA AVAILABILITY STATEMENT}

The raw data supporting the conclusions of this article will be made available by the authors, without undue reservation.

\section{ETHICS STATEMENT}

This study was approved by the University of Valencia's Human Research Ethics Committee (H1549280336722). The patients/participants provided their written informed consent to participate in this study. 


\section{AUTHOR CONTRIBUTIONS}

All authors listed have made a substantial, direct and intellectual contribution to the work, and approved it for publication.

\section{REFERENCES}

1. Kessler RC, Angermeyer M, Anthony JC, de Graaf R, Koen D, Gasquet I, et al. Lifetime prevalence and age-of-onset distributions of mental disorders in the World Health Organization's World Mental Health Survey Initiative. World Psychiatry. (2007) 6:168-76.

2. Polanczyk GV, Salum GA, Sagaya LS, Caye A, Rohde LA. Annual research review: a meta-analysis of the worldwide prevalence of mental disorders in children and adolescents. J Child Psychol Psychiatry. (2015) 56:34565. doi: 10.1111/jcpp.12381

3. Remes $\mathrm{O}$, Brayne $\mathrm{C}$, van der Linde R, Lafortune, L. A systematic review of reviews on the prevalence of anxiety disorders in adult populations. Brain Behav. (2016) 6:e00497. doi: 10.1002/brb3.497

4. Lijster JM, Dierckx B, Utens EM, Verhulst FC, Zieldorff C, Dieleman GC, et al. The age of onset of anxiety disorders: a meta-analysis. Can J Psychiatry. (2016) 62:237-46. doi: 10.1177/0706743716640757

5. Essau CA, Lewinsohn PM, Lim JX, Ho MR, Rohde P. Incidence, recurrence and comorbidity of anxiety disorders in four majordevelopmental stages. $J$ Affec Disord. (2018) 228:248-53. doi: 10.1016/j.jad.2017.12.014

6. LeBlanc NJ, Mackenzie B, Aude, H. Anxiety disorders in emerging adulthood. In: Bui E, Charney M, Baker A, editors. Clinical Handbook of Anxiety Disorders. Switzerland: Springer Nature Switzerland AG (2020). p.157-73.

7. Essau CA, Lewinsohn PM, Olaya B, Seeley JR. Anxiety disorders in adolescents and psychosocial outcomes at age 30. J Affec Disord. (2014) 163:12532. doi: 10.1016/j.jad.2013.12.033

8. Rogers AH, Wieman ST, Baker AW. Anxiety comorbidities: mood disorders, substance use disorders, and chronic medical illness. In: Bui E. Charney M, Baker A, editors. Clinical Handbook of Anxiety Disorders. Switzerland: Springer Nature Switzerland AG. (2020). p. 77-104.

9. Black JJ, Rofey DL. An overview of common psychiatric problems among adolescent and young adult females: focus on mood and anxiety. Best Pract Res Clin Obstet and Gynaecol. (2018) 48:165-73. doi: 10.1016/j.bpobgyn.2017.08.007

10. Boden JM, Fergusson DM, Horwood LJ. Anxiety disorders and suicidal behaviours in adolescence and young adulthood: findings from a longitudinal study. Psychol Med. (2007) 37:431-40. doi: 10.1017/S0033291706009147

11. Ahmadpoor J, Mohammadi Y, Soltanian AR, Poorolajal J. Psychiatric disorders and associated risky behaviors among Iranian university students: results from the Iranian PDABs survey. J Public Health. (2020), 18. doi: 10.1007/s10389-020-01229-8

12. Dennis RE, Boddington SJ, Funnell NJ. Self-report measures of anxiety: are they suitable for older adults? Aging Mental Health. (2007) 11:66877. doi: 10.1080/13607860701529916

13. Iglesias García C, López García P, Ayuso Mateos JL, García JA, Bobes J.Screening for anxiety depression in Primary Care: utility of 2 brief scales adapted to the new ICD-11-PC. Rev Psiquiatr Salud Ment. (2020) 30. S18889891(20)30014-8. doi: 10.1016/j.rpsm.2019.12.001

14. Balsamo M, Cataldi F, Fairfield B. Assessment of anxiety in older adults: a review of self-report measures. Clin Interv Aging. (2018) 13:57393. doi: 10.2147/CIA.S114100

15. Vasa RA, Keefer A, Reaven J, South M, White SW. Priorities for advancing research on youth with autism spectrum. J Autism Dev Disord. (2018) 48:92534. doi: 10.1007/s10803-017-3320-0

16. Sandin B, Chorot P, Valiente, RM. TCC de los Trastornos de Ansiedad: Innovaciones en niños y Adolescentes. Madrid: Klinic (2016).

17. Simon E, Bögels SM. Screening for anxiety disorders in children. Eur Child Adolesc Psychiatry. (2009) 18:625-34. doi: 10.1007/s00787-0090023-x

18. Spielberger C, Gorsuch R, Lushene R, Vagg P, Jacobs G. Manual for the StateTrait Anxiety Inventory. Palo Alto, CA: Consulting Psychologists Press (1983).

\section{SUPPLEMENTARY MATERIAL}

The Supplementary Material for this article can be found online at: https://www.frontiersin.org/articles/10.3389/fpsyt. 2021.589422/full\#supplementary-material

19. Beck A, Steer R. Beck Anxiety Inventory Manual. San Antonio, TX: The Psychological Corporation (1993); Spanish version (2011).

20. Muñiz J, Fernández-Hermida JR. La opinión de los psicólogos españoles sobre el uso de los tests. Papeles Psicól. (2010) 31:108-21. Available online at: http:// www.papelesdelpsicologo.es/pdf/1801.pdf

21. Sanz J. Recomendaciones para la utilización de la adaptación española del Inventario de Ansiedad de Beck (BAI) en la práctica clínica. Clin Salud. (2014) 25:39-48. doi: 10.1016/S1130-5274(14)70025-8

22. Bados A, Solanas A, Andrés R. Psychometric properties of the Spanish version of depression, anxiety and stress scales (DASS). Psicothema. (2005) 17:679-83. Available online at: http://www.psicothema.com/pdf/3165.pdf

23. García-Campayo J, Zamorano E, Ruiz MA, Pardo A, Pérez-Páramo M, LópezGómez V Freire, et al. Cultural adaptation into Spanish of the generalized anxiety disorder-7 (GAD-7) scale as a screening tool. Health Qual Life Outcomes. (2010) 8:8. doi: 10.1186/1477-7525-8-8

24. García-López LG, Bermejo RM, HidalgoMD. The social phobia inventory: screening and cross-cultural validation in Spanish adolescents. Span J Psychol. (2010) 13:970-80. doi: 10.1017/S1138741600002614

25. Bobes J, Badía X, Luque A, García M, Paz González M, Dal-Ré R.Validación de las versiones en español de los cuestionarios Liebowitz Social Anxiety Scale, Social Anxiety and Distress Scale y Sheehan Disability Inventory para la evaluación de la fobia social. Med Clin. (1999) 112:530-8.

26. Santacana M, Fullana MA, Bonillo A, Morales M, Montoro M, Rosado $\mathrm{S}$, et al. Psychometric properties of the Spanish sel-report version of the Panic Disorder Severity Scale. Compr Psychiatry. (2014) 55:146772. doi: 10.1016/j.comppsych.2014.04.007

27. Kendall P, Compton S, Walkup J, Birmaher B, Albano A, Sherrill J., et al. Clinical characteristics of anxiety disordered youth. J Anxiety Disord. (2010) 24:360-65. doi: 10.1016/j.janxdis.2010.01.009

28. American Psychiatric Association. Diagnostic and Statistical Manual of Mental Disorders: DSM-5. Arlington, VA: Asociación Americana de Psiquiatría (2013).

29. Angulo M, Rooks BT, Gill M, Goldstein T,Sakolsky, D, Goldstein, et al. Psychometrics of the screen for adult anxiety related disorders (SCAARED)A new scale for the assessment of DSM-5 anxiety disorders. Psychiatry Res. (2017) 253:84-90. doi: 10.1016/j.psychres.2017.02.034

30. Birmaher B, Khetarpal S, Brent D, Cully M, Balach L, Kaufman J, et al. The Screen for Child Anxiety Related Emotional Disorders (SCARED): scale construction and psychometric characteristics. J Am Acad Child Adolesc Psychiatry. (1997) 36:545-53. doi: 10.1097/00004583-19970400000018

31. Birmaher B, Brent DA, Chiappetta L, Bridge J, Monga S, Baugher M. Psychometric properties of the Screen for Child Anxiety Related Emotional Disorders (SCARED): a replication study. J Am Acad Child Adolesc Psychiatry. (1999) 38:1230-36. doi: 10.1097/00004583-199910000-00011

32. Hale WW 3rd., Crocetti E., Raaijmakers QA, Meeus WH. A meta-analysis of the cross-cultural psychometric properties of the Screen for Child Anxiety Related Emotional Disorders (SCARED). J Child Psychol Psychiatry. (2011) 52:80-90. doi: 10.1111/j.1469-7610.2010.02285.x

33. Canals J, Hernández-Martínez $\mathrm{C}$, Cosi S, Domènech E. Examination of a cutoff score for the Screen for Child Anxiety Related Emotional Disorders (SCARED) in a non-clinical Spanish population. J Anxiety Disord. (2012) 26:785-91. doi: 10.1016/j.janxdis.2012.07.008

34. Vigil-Colet A, Canals J, Cosi S, Lorenzo-Seva U, Ferrando PJ, HernándezMartínez C, et al. The factorial structure of the 41-item version of the Screen for Child Anxiety Related Emotional Disorders (SCARED) in a Spanish population of 8 to 12 years-old. Int J Clin Health Psychol. (2009) 9:313-27. Available online at: https://www.redalyc.org/pdf/337/33712028009.pdf

35. Román F, Santibáñez P, Vinet EV. Uso de las Escalas de Depresión Ansiedad Estrés (DASS-21) como Instrumento de Tamizaje en 
Jóvenes con Problemas Clínicos. Acta de Investig Psicol. (2016) 6:2325-36. doi: 10.1016/S2007-4719(16)30053-9

36. Buela-Casal G, Guillén-Riquelme A, Seisdedos Cubero N. Cuestionario de Ansiedad Estado-Rasgo. Octava edición. Madrid: TEA Ediciones (2011).

37. Lovibond $\mathrm{P}$, Lovibond $\mathrm{S}$. The structure of negative emotional states: comparison of the Depression Anxiety Stress Scales (DASS) with the beck depression and anxiety inventories. Behav Res Ther. (1995) 33:33543. doi: 10.1016/0005-7967(94)00075-U

38. Sheehan D, Janavs J, Baker R, Harnett-Sheehan K, Knapp E, Sheehan M, et al. MINI International Neuropsychiatric Interview (5,0,0 version). Tampa, FL (2006). Available online at: http://www.iiap.es/files/mini.pdf (accessed January 12, 2020).

39. Muñiz J, Elosua P, Hambleton R. Directrices para la traducción y adaptación de los tests: segunda edición. Psicothema. (2013) 25:151-57. doi: 10.7334/psicothema2013.24

40. Daza P, Novy D, Stanley M, Averill P. The depression anxiety stress scale21: Spanish translation and validation with a Hispanic sample. J Psychopathol Behav Assess. (2002) 24:195-205. doi: 10.1023/A:1016014818163

41. Fonseca-Pedrero E, Paino M, Lemos-Giráldez S, Muñiz, J. Psychometric properties of the Depression Anxiety and Stress Scales-21 (DASS-21) in Spanish college students. Ansiedad Estrés. (2010) 16:215-26.

42. Sanz J, Navarro ME. Propiedades psicométricas de una versión española del Inventario de Ansiedad de Beck (BAI) en estudiantes universitarios. Ansiedad Estrés. (2003) 9:59-84. Available online at: https://www.researchgate. net/publication/285908290_Propiedades_psicometricas_de_una_version_ espanola_del_Inventario_de_Ansiedad_de_Beck_BAI_en_estudiantes_ universitarios

43. Magán I, Sanz J, García-Vera MP. Psychometric properties of a Spanish version of the Beck Anxiety Inventory (BAI) in general population. Span J Psychol. (2008) 11:626-40. doi: 10.1017/S113874160000 4637

44. Sanz J, García-Vera M, Fortún M. El "Inventario de Ansiedad de Berck" (BAI): propiedades psicométricas de la versión española en pacientes con trastornos psicológicos. Psicol Conductual. (2012) 20:563-83. Available online at: https://www.behavioralpsycho.com/wp-content/uploads/2019/08/ 05.Sanz_20-3oa.pdf

45. Vázquez-Morejón A, Vázquez-Morejón R, Bellido-Zanin BG. Beck anxiety inventory: psychometric characteristics in a sample from the clinical Spanish population. Span J Psychol. (2014) 17:E761 doi: 10.1017/sjp.2014.76 (accessed November 10, 2020).

46. Muthén LK, Muthén BO. Mplus User's Guide. Los Angeles, CA: Muthén \& Muthén (2017). Available online at: http://www.statmodel.com/download/ usersguide/MplusUserGuideVer_8.pdf (accessed November 10, 2020).

47. Cerny BA, Kaiser HF. A study of a measure of sampling adequacy for factor-analytic correlation matrices. Multivariate Behav Res. (1977) 12:43-7. doi: 10.1207/s15327906mbr1201_3

Conflict of Interest: The authors declare that the research was conducted in the absence of any commercial or financial relationships that could be construed as a potential conflict of interest.

Copyright (C) 2021 Sánchez-Cueva, Alonso-Esteban, Sánchez-Cueva, Birmaher and Alcantud-Marin. This is an open-access article distributed under the terms of the Creative Commons Attribution License (CC BY). The use, distribution or reproduction in other forums is permitted, provided the original author(s) and the copyright owner(s) are credited and that the original publication in this journal is cited, in accordance with accepted academic practice. No use, distribution or reproduction is permitted which does not comply with these terms. 